\title{
A fuzzy neural network to estimate at completion costs of construction projects
}

\author{
Mohammad Reza Feylizadeh $^{\mathrm{a}^{*}}$, Ayad Hendalianpour ${ }^{\mathrm{b}}$ and Morteza Bagherpour $^{\mathrm{c}}$
}

\author{
${ }^{a}$ Department of Industrial Engineering, Shiraz Branch, Islamic Azad University, Shiraz, Iran \\ ${ }^{b}$ Soshianest Industrial Research Center, North Motahari Avenue, Shiraz, Iran \\ ${ }^{c}$ Department of Industrial Engineering, Iran University of Science and Technology, Tehran, Iran

\begin{tabular}{|c|c|}
\hline A R T I C L E I N F O & A B S T R A C T \\
\hline $\begin{array}{l}\text { Article history: } \\
\text { Received } 20 \text { September } 2011 \\
\text { Received in revised form } \\
\text { November, } 2,2011 \\
\text { Accepted November, } 182011 \\
\text { Available online } \\
25 \text { November } 2011 \\
\text { Keywords: } \\
\text { EAC } \\
\text { Earned value management }\end{array}$ & $\begin{array}{l}\text { In construction cost management system, normally earned value management (EVM) is applied } \\
\text { as an efficient control approach in both status detection and estimation at completion (EAC) } \\
\text { cost forecasting. The traditional approaches in EAC predictions normally extend the current } \\
\text { situation of a project to the future by employing pervious performance factor. The proposed } \\
\text { approach of this paper considers both qualitative and quantitative factors affecting the EAC } \\
\text { prediction. The proposed approach of this research not only estimates the completion of the } \\
\text { project, but also it can generate accurate forecast for the entire future periods using a fuzzy } \\
\text { neural network model. The model is also implemented for a real-world case study and yields } \\
\text { encouraging preliminary results. }\end{array}$ \\
\hline
\end{tabular} \\ Fuzzy neural network
}

Construction cost management

\section{Introduction}

Project cost management is one of important issues in project management systems. In project cost management system, earned value management (EVM) is efficiently applied through many projects and industries. A work package methodology was offered by Howes (2000) to improve the performance of EVA by employing the combination of work packages and logical time analysis. Kim et al. (2003) proposed a model to address EVM problems, improving utilities and taking project environment, implementation process, EVM users and methodology. Alvarado (2004) presented techniques to use EVM principles to analyze the portfolios of construction projects and to incorporate the analysis into an innovative pay-for-performance human resources practice.

Fleming and Koppelman (2005) presented a general form of EVM, which makes it possible to apply for large-scale projects. Vandevoorde and Vanhoucke (2006), as a novel work, compared the classical earned value performance indicators (SV and SPI) with the recently developed earned schedule performance indices called (SV (t) and SPI (t)). They also proposed a new formulation for a generic schedule forecasting, which was used in various project circumstances and compared the performance of the methods in terms of total project duration with other methods. Cioffi (2006) offered a new formulation for EVM, which helps earned value calculations to become more flexible. Jigeesh and

* Corresponding author Tel: +989177125179

E-mail: feylizadeh_mr@yahoo.com (M. R. Feylizadeh)

(C) 2012 Growing Science Ltd. All rights reserved. doi: $10.5267 /$ j.jijiec.2011.11.003 
Bhat (2006) concentrated on project control system and extended the EVM concept for dynamic environment based on simulation techniques. Noori et al. (2008a) presented a fuzzy control chart approach considering a-cut to control earned value performance indexes including linguistics terms. In addition, a new application, based on a multi period-multi product (MPMP) production control problem was illustrated and successfully implemented. In other work, Noori et al. (2008b) presented how a mechanism for controlling MPMP can be created by applying fuzzy EVM. They also showed production planning problem (PPP) can be successfully integrated with powerful project control tools.

By developing an efficient forecasting method, Lipke et al. (2009) increased the project managers' capabilities to make better managerial decisions. In order to analyze schedule performance, it also used a well established project management method. Discussing two different perceptions of the EVM concept, Fleming and Koppelman (2010) generalized the concept of EVM using many best practice and real-world case studies. They also reported that the concept of EVM can be successfully implemented for virtually any project in any size in different industries. Bagherpour et al. (2010) modeled the uncertainty associated with activity duration in earned value analysis. The approach incorporated a control approach, which is applicable within production control. Costs were assumed to be directly associated with fuzzy activity time estimated through a bottom up hierarchy process.

Chou et al. (2010) proposed a visual architecture, design and implementation based on Web to evaluate a project performance regarding combination of EVA and database management system. Pjares (2010) presented combination of EVM and project risk management to control and monitor the projects. In this work, the cost and schedule control indices were introduced. Moslemi et al. (2011) offered a new model based on fuzzy logic. They employed this model for estimating cost and time at completion under uncertainty considering earned value indices. Moslemi and salehipour (2011) used fuzzy earned value indices combining with $\alpha$-cut method. This work were employed to make earned value techniques more applicable under real-life and nondeterministic situations. A model was developed by Warburton (2011) for demonstrating how to estimate final cost of the projects with faster coverage to the appropriate result and less variation than estimate-at-completion (EAC) calculations.

\section{Fuzzy neural network adaption for EAC forecasting}

Neural networks consist of a series of simple processors called "Unit" and they communicate with each other by communicative channels called connections. The output of each individual unit is obtained by setting up different randomized weight values and Bias within a unit. The neural networks systematically adjust the weight amounts of connections and Bias ranges of each unit in different levels of the network architecture through applying a learning structure by employing training data, so that a considerable accuracy is obtained for the approximations of the network's output amount. In addition, in neural networks, the output of network is affected by the amounts of connection's weight, unit's Bias and input data of network. In a fuzzy inference system, obtaining the result is possible through fuzzy number via using neural networks and receiving input amounts or parameters of network through fuzzy numbers or combining both fuzzy and certain numbers. In some other works, to expand fuzzy inference capabilities by neural networks, some models were represented for input and output data through fuzzy conditions and certain amounts for network's parameters, fuzzy input and output and fuzzy parameters through triangular numbers (Ishibuchi et al., 1992). Ishibuchi (1992) presented a method based on fuzzy neural networks with triangular fuzzy weights. The proposed fuzzy neural network handles fuzzy input vectors as well as real data. He also defined a cost function for different alpha cuts of fuzzy targets and derived a learning algorithm from the cost function to adjust three parameters of each triangular fuzzy weight. The output of the network is represented through fuzzy numbers and the primary issue is on how to calculate the output of network and how to train the algorithm. 


\subsection{Calculating the output of fuzzy neural network}

The architecture of the fuzzy neural network is shown in Fig. 1 to calculate the total costs needed for project completion.

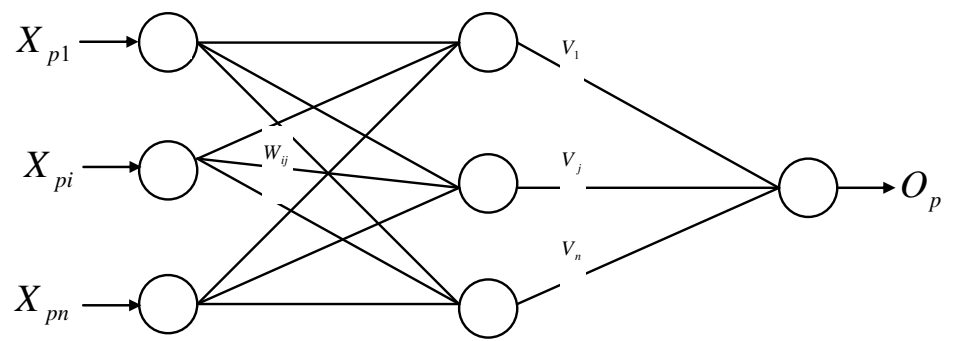

Fig. 1. Architecture of the fuzzy neural network

The input and output relationships of fuzzy neural network's units of Fig. 1 are as the followings:

- Inputs units:

$O_{p i}=X_{p i}, i=1,2, \ldots, n$.

- Hidden units:

$O_{p j}=f\left(\right.$ Net $\left._{p j}\right), j=1,2, \ldots, m$

$N e t_{p j}=\sum_{i=1}^{n} W_{i j} \cdot O_{p i}+B_{j}$,

- Output units:

$O_{p}=f\left(\right.$ Net $\left._{p}\right)$,

$N e t_{p}=\sum_{j=1}^{m} V_{j} \cdot O_{p k}+B$

$O_{p k}=A C+\frac{B A C-E V}{w_{1} C P I+w_{2} S P I}+A_{1}+A_{2}+A_{3}$,

where $w_{1}+w_{2}=1$

On the other hand, in many projects, EAC is affected not only by quantitative parameters such as cost, progress, etc., but also by qualitative factors such as weather condition, employer cash status, degree of experience for project staff stated as A1, A2, and A3.

$A_{1} \cdot A_{2}, A_{3}$ are :

$A_{1}:$ Employer cash status

- Good

- Middle

- $\mathrm{Bad}$

$A_{2}$ : Work experience of teams

- Very Much

- Middle

- Little

$A_{3}$ : Weather status

- Good

- Middle

- $\mathrm{Bad}$

$A_{1} \cdot A_{2}, A_{3}$ are fuzzy input. 
Let $\mathrm{P}$ be the number of input vectors, $X_{p i}$ be the $i^{\text {th }}$ element of vector $\mathrm{p}, W_{i j}$ and $V_{j}$ be the weight of connections, $B_{j}$ and $B$ be the bias amount of units and $O_{p}$ be the amount of network's output, respectively. $O_{p}$ is equivalent to the whole satisfaction of customer for the product or received service in the customer satisfaction measurement model. The expression $f(x)=1 /(1+\exp (-x))$ is as the activation function of the neural network.

On the basis of the definition of h-level cut of fuzzy numbers, the input and output relationships of neural network's units are as the followings with the fuzzy parameters and inputs:

- Inputs units:

$\left[O_{p i}\right]_{h}=\left[X_{p i}\right]_{h}$

- Hidden units:

$\left[O_{p j}\right]=f\left(\left[N_{p j}\right]_{h}\right.$,

$\left[N e t_{p j}\right]_{h}=\sum_{i=1}^{n}\left[W_{i j}\right]_{h} \cdot\left[O_{p i}\right]_{h}+\left[B_{j}\right]_{h}$.

- Output units:

$\left[\mathrm{O}_{p}\right]=f\left(\left[\mathrm{Net}_{p}\right]_{h}\right.$,

$\left[\text { Net }_{p}\right]_{h}=\sum_{j=1}^{m}\left[V_{j}\right]_{h} \cdot\left[O_{p j}\right]_{h}+[B]_{h}$.

Since the input data are positive we can use Eq. (6), Eq. (7) and Eq. (8) to express the fuzzy neural network as follows,

- Inputs units:

$\left[O_{p i}\right]_{h}=\left[\left[O_{p i}\right]_{h}^{l},\left[O_{p i}\right]_{h}^{u}\right]=\left[\left[X_{p i}\right]_{h}^{l},\left[X_{p i}\right]_{h}^{u}\right]$

- Hidden units:

$\left[O_{p j}\right]_{h}=\left[\left[O_{p j}\right]_{h}^{l},\left[O_{p j}\right]_{h}^{u}\right]=\left[f\left[N t_{p j}\right]_{h}^{l}, f\left[N e t_{p j}\right]_{h}^{u}\right]$

$\left[\mathrm{Net}_{p j}\right]_{h}^{l}=\sum_{i=1}^{n}\left[W_{i l}\right]_{h}^{l} \cdot\left[O_{p i}\right]_{h}^{l}+\sum_{i=1}^{n}\left[W_{i l}\right]_{h}^{l} \cdot\left[O_{p i}\right]_{h}^{u}+\left[B_{j}\right]_{h}^{l}$

$\left[W_{i j}\right]_{h}^{l} \geq 0 \quad\left[W_{i j}\right]_{h}^{l} \leq 0$

$\left[N e t_{p j}\right]_{h}^{u}=\sum_{i=1}^{n}\left[W_{i l}\right]_{h}^{u} \cdot\left[O_{p i}\right]_{h}^{u}+\sum_{i=1}^{n}\left[W_{i l}\right]_{h}^{u} \cdot\left[O_{p i}\right]_{h}^{l}+\left[B_{j}\right]_{h}^{u}$

$\left[W_{i j}\right]_{h}^{u} \geq 0 \quad\left[W_{i j}\right]_{h}^{u} \leq 0$

- Output units:

$\left[O_{p}\right]_{h}=\left[\left[O_{p}\right]_{h}^{l},\left[O_{p}\right]_{h}^{u}\right]=\left[f\left[N^{2} t_{p}\right]_{h}^{l}, f\left[N e t_{p}\right]_{h}^{u}\right]$

$\left[N e t_{p}\right]_{h}^{l}=\sum_{j=1}^{m}\left[V_{j}\right]_{h}^{l} \cdot\left[O_{p j}\right]_{h}^{l}+\sum_{j=1}^{m}\left[V_{j}\right]_{h}^{l} \cdot\left[O_{p}\right]_{h}^{u}+[B]_{h}^{l}$

$\left[V_{j}\right]_{h}^{l} \geq 0 \quad\left[V_{j}\right]_{h}^{l} \leq 0$ 
$\left[N e t_{p}\right]_{h}^{u}=\sum_{j=1}^{m}\left[V_{j}\right]_{h}^{u} \cdot\left[O_{p j}\right]_{h}^{u}+\sum_{j=1}^{m}\left[V_{j}\right]_{h}^{u} \cdot\left[O_{p}\right]_{h}^{l}+[B]_{h}^{u}$

$\left[V_{j}\right]_{h}^{u} \geq 0 \quad\left[V_{j}\right]_{h}^{u} \leq 0$

On the basis of above formulas, through changing the amount of $h$ in intervals $[0,1]$, the membership grade function of the fuzzy number of the network's output is calculated.

\subsection{Learning procedure in the fuzzy neural network}

If $T_{p}$ is the target amount and $O_{p}$ is the output amount of the neural network and it is analogous with the input vector $X_{p}=\left(X_{p 1}, X_{p 2}, \ldots, X_{p n}\right)$ the error amount of the neural network's operation is calculated through defining the cost function. In the fuzzy neural model, the cost function in the hlevel cut is defined using the followings (Grigoroudis \& Siskos 2002),

$$
\begin{aligned}
& e_{p h}=e_{p h}^{l}+e_{p h}^{u}, \\
& e_{p h}^{l}=h \cdot \frac{\left(\left[T_{p}\right]_{h}^{l}-\left[O_{p}\right]_{h}^{l}\right)^{2}}{2}, \\
& e_{p h}^{u}=h \cdot \frac{\left(\left[T_{p}\right]_{h}^{u}-\left[O_{p}\right]_{h}^{u}\right)^{2}}{2} .
\end{aligned}
$$

The amount of $e_{p h}^{l}$ and $e_{p h}^{u}$ are in the cut-level $h$ from squares of high-limit and low-limit errors, respectively, which have been weighted with coefficients of $\frac{h}{2}$. Alteration of " $h$ " amounts in interval $[0,1]$ of the cost function for the input vector $p$ is follows,

$e_{p}=\sum_{h} e_{p h}$.

In the learning process, the first amounts of the network's parameters are reformed by using cost function in a way that their triangular structure is still kept and the amounts of beginning, ending and width of the triangular fuzzy number change through decreasing the output error of the network. The triangular fuzzy numbers of network's weights and Bias are as follows,

$$
\begin{aligned}
& W_{i j}=\left(W_{i j}^{l}, W_{i j}^{c}, W_{i j}^{u}\right) \quad V_{j}=\left(V_{j}^{l}, V_{j}^{c}, V_{j}^{u}\right) \\
& B_{j}=\left(B_{j}^{l}, B_{j}^{c}, B_{j}^{u}\right) \quad B=\left(B^{l}, B^{c}, B^{u}\right)
\end{aligned}
$$

The superscripts $L, C$ and $V$ in Eq. (12) are low, central and above limits of triangular fuzzy numbers, respectively and the centers are determined as follow,

$$
\begin{aligned}
& W_{i j}^{c}=\frac{W_{i j}^{l}+W_{i j}^{u}}{2}, V_{j}^{c}=\frac{V_{j}^{l}+V_{j}^{u}}{2}, \\
& B_{j}^{c}=\frac{B_{j}^{l}+B_{j}^{u}}{2}, B=\frac{B^{l}+B^{u}}{2} .
\end{aligned}
$$

On the basis of the cost function $e_{p h}$, the modified amount of each parameters of the network is calculated as the sample $6 V_{j}$ :

$$
\begin{aligned}
& \Delta V_{j}^{l}(t)=-\eta \cdot \frac{\partial e_{p h}}{\partial V_{j}^{l}}+\alpha \cdot \Delta V_{j}^{l}(t-1), \\
& \Delta V_{j}^{u}(t)=-\eta \cdot \frac{\partial e_{p h}}{\partial V_{j}^{u}}+\alpha \cdot \Delta V_{j}^{u}(t-1) .
\end{aligned}
$$


where $\eta$ is the learning constant, $\alpha$ is the movement amount constant and $t$ is the modification number. Due to the triangular fuzzy symmetry assumption, the center's amounts of the network's parameters are obtained by using Eq. (12). The high and low limits of interval resolved by h-level cut are written as follow,

$\left[V_{j}\right]_{h}=\left[\left[V_{j}\right]_{h}^{l},\left[V_{j}\right]_{h}^{u}\right]$,

$\left[V_{j}\right]_{h}^{l}=V_{j}^{l}\left(1-\frac{h}{2}\right)+V_{j}^{u} \cdot \frac{h}{2}$,

$\left[V_{j}\right]_{h}^{u}=V_{j}^{l} \cdot \frac{h}{2}+V_{j}^{u}\left(1-\frac{h}{2}\right)$.

$\frac{\partial e_{p h}}{\partial V_{j}^{u}}=\frac{1}{2} \cdot \frac{\partial e_{p h}}{\partial\left[V_{j}\right]_{h}^{l}} \cdot \frac{\partial\left[V_{j}\right]_{h}^{l}}{\partial V_{j}^{u}}+\frac{1}{2} \cdot \frac{\partial e_{p h}}{\partial\left[V_{j}\right]_{h}^{u}} \cdot \frac{\partial\left[V_{j}\right]_{h}^{u}}{\partial V_{j}^{u}}$.

Using Eq. (14), yields the following,

$\frac{\partial e_{p h}}{\partial V_{j}^{l}}=\frac{1}{2} \cdot \frac{\partial e_{p h}}{\partial\left[V_{j}\right]_{h}^{l}}\left(1-\frac{h}{2}\right)+\frac{1}{2} \cdot \frac{\partial e_{p h}}{\partial\left[V_{j}\right]_{h}^{u}} \cdot \frac{h}{2}$,

$\frac{\partial e_{p h}}{\partial V_{j}^{u}}=\frac{1}{2} \cdot \frac{\partial e_{p h}}{\partial\left[V_{j}\right]_{h}^{l}} \cdot \frac{h}{2}+\frac{1}{2} \cdot \frac{\partial e_{p h}}{\partial\left[V_{j}\right]_{h}^{u}}\left(1-\frac{h}{2}\right)$.

Grigoudis and Siskos (2002) presented an easier way for calculating $\frac{\partial e_{p h}}{\partial\left[V_{j}\right]_{h}^{l}}$ and $\frac{\partial e_{p h}}{\partial\left[V_{j}\right]_{h}^{u}}$, which is also similar to calculations of $W_{i j}, B_{j}, B$. On the basis of obtained amounts for modifying $\Delta V_{j}(t)$, the weights $V_{j}=\left(V_{j}^{l}, V_{j}^{c}, V_{j}^{u}\right)$ are obtained as follows,

$V_{j}^{l}(t+1)=V_{j}^{l}(t)+\Delta V_{j}^{l}(t)$

$V_{j}^{u}(t+1)=V_{j}^{u}(t)+\Delta V_{j}^{u}(t)$

$V_{j}^{c}(t+1)=\frac{V_{j}^{l}(t+1)+V_{j}^{u}(t+1)}{2}$.

After modifying $V_{j}$, if the low limit is bigger than the high limit, the amounts of high and low limits are as follows,

$V_{j}^{l}(t+1)=\min \left\{V_{j}^{l}(t+1), V_{j}^{u}(t+1)\right\}$,

$V_{j}^{u}(t+1)=\max \left\{V_{j}^{l}(t+1), V_{j}^{u}(t+1)\right\}$.

Reforming all the parameters of the fuzzy neural network, $W_{i j}, B_{j}, B$, is performed similar to " $V_{j}$ ".

Briefly, learning in the fuzzy neural network is done through the following algorithm.

Step1: Initialize parameters of neural network, weights and Bias of units,

Step2: Repeat step 3 for cut levels $h=h_{1}, h_{2}, \ldots, h_{n}$,

Step3: Repeat for input data $P=1,2, \ldots, m$

- In the cut level " $h$ ", the output amounts of the neural network, calculate $O_{p}$ for the analogous input vector $X_{p}$,

- Modify the first amount of network's parameters using the cost function $e_{p h}$,

Step4: Stop if the terminating conditions are met, otherwise repeat the algorithm. 


\section{Comparative analysis}

In this section, we demonstrate the proposed learning algorithm by a computer simulation model for some examples and the results are shown in Fig. 2. In this illustration, we apply the Fuzzy Neural Network (FNN) method to forecast EAC with fuzzy function and some exact data. The effective specifications on the relationship between cost system and fuzzy neural network are shown in Table 1.

Table 1

Set of all attributes

\begin{tabular}{|c|c|c|c|}
\hline Attributes & Abbreviation & Description & Type \\
\hline Q1 & $\mathrm{AC}$ & Actual costs & Quantitative \\
\hline Q2 & $\mathrm{BAC}$ & Budget at Completion & Quantitative \\
\hline Q3 & $\mathrm{EV}$ & Earned Value & Quantitative \\
\hline Q4 & PV & Planned Value & Quantitative \\
\hline Q5 & CPI & Cost Performance Index & Quantitative \\
\hline Q6 & SPI & Schedule Performance Index & Quantitative \\
\hline Q7 & A1 & Employer Cash status & Qualitative \\
\hline Q8 & $\mathrm{A} 2$ & Weather condition & Qualitative \\
\hline Q9 & A3 & Experience of project staff & Qualitative \\
\hline
\end{tabular}

The results of fuzzy neural forecasting and the exact EAC are compared in Fig. 2.

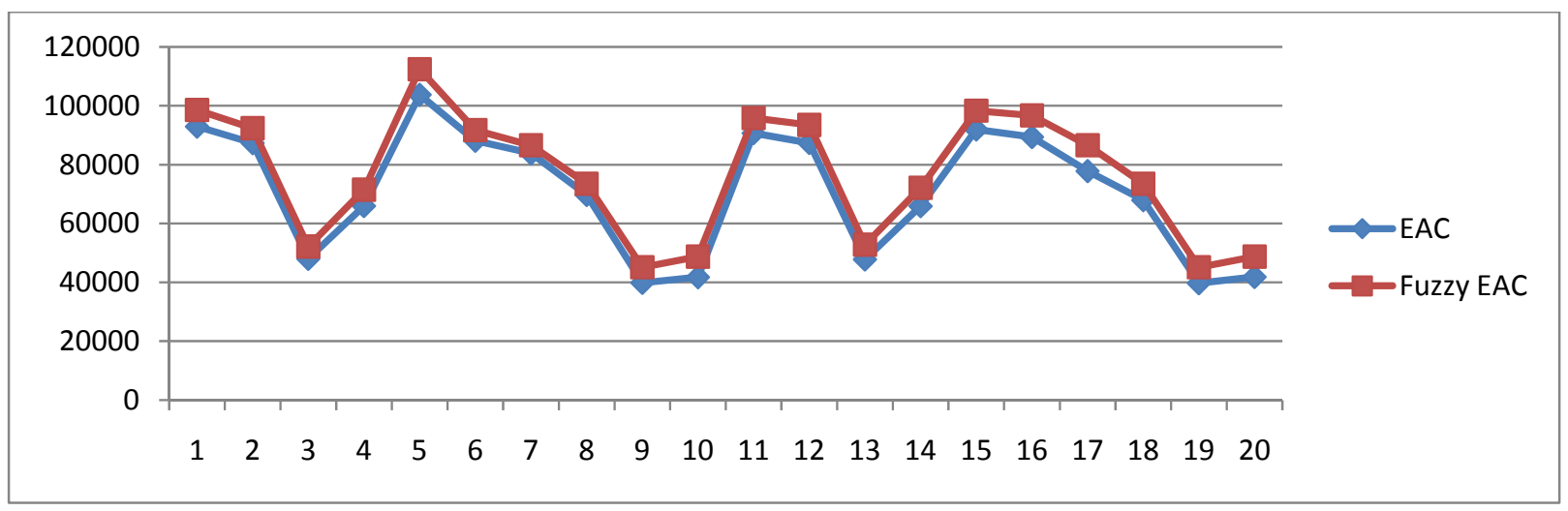

Fig. 2. Comparative analysis of forecasting model and actual data

As we can observe from the results of Fig. 2, the proposed model of this paper tends to perform better than the traditional method. One obvious observation is that the proposed model of this paper considers the negative impacts of many qualitative factors such as employer cash status, work experience of project staff and weather condition, etc.

\section{Conclusion remark and further recommendation}

In this paper, we have presented a novel EAC model, which considers several qualitative factors in addition to many other quantitative factors. The proposed model of this paper uses a fuzzy neural model, which handles uncertainty associated with the data. The proposed model was trained and the results were compared with the traditional EAC forecasting approach. The approach can be further used for forecasting any period in the future (not just takes at completion costs). The proposed approach given in this paper can help contractors consider qualitative inputs affecting on the EAC forecasting. Further recommendation can be made on constructing a framework for better dealing between contractor and employer where some claims on behalf of contractor is raised.

\section{Acknowledgements}

The author wishes to express his acknowledgement for financial support of this research under grant number 90/213 given by Shiraz Branch of Islamic Azad University. 


\section{References}

Alvarado, C. M., Silverman, R. P., \& Wilson, D. S. (2004). Assessing the performance of construction projects: Implementing earned value management at the General Services Administration. Journal of Facilities Management, 3(1), 92-105.

Bagherpour M., Zareei A., Noori S., \& Heydari M. (2010). Designing a control mechanism using earned value analysis: an application to production environment. International Journal of Advanced Manufacturing Technology, 40, 419-429.

Chou J.-S., Chen H.-M., Hou C.-C., \& Lin C.-W. (2010). Visualized EVM system for assessing project performance. Automation in Construction, 19, 596-607.

Cioffi, D. F. (2006). Designing project management: A scientific notation and an improved formalism for earned value calculations. International Journal of Project Management, 24, 136-144.

Fleming, Q. W., \& Koppelman, J. M. (2005). Earned Value Project Management (3rd Edition): Project Management Institute, Newtown Square, PA.

Fleming, Q. W., \& Koppelman, J. M. (2010). Earned Value Project Management (Fourth Edition): Project Management Institute.

Grigoroudis, E., \& Siskos, Y. (2002). Preference disaggregation for measuring and analyzing customer satisfaction: The MUSA method. European Journal of Operational Research, 143(1), 148-170.

Howes, R. (2000). Improving the performance of Earned Value Analysis as a construction project management tool. Engineering, Construction and Architectural Management, 7(4), 399 - 411.

Ishibuchi, H., Fujioka, R., \& Tanaka, H. (1992). An architecture of neural network for input vectors of fuzzy numbers. IEEE International Conference on Fuzzy System, San Diego, CA, USA, 12931300.

Ishibuchi, H., Kwon, K., \& Tanaka, H.( 1995). A learning algorithm of fuzzy neural networks with triangular fuzzy weights. Fuzzy Sets and Systems, 71(3) 277-293.

Jigeesh, N., \& Bhat, M. S. (2006). Modeling and simulating the dynamics in project monitoring and earned value analysis. Journal of Advances in Management Research, 3(1), $26-43$.

Kim, E., Wells Jr., W. G., \& Duffey, M. R. (2003). A model for effective implementation of Earned Value Management methodology. International Journal of Project Management, 21, 375-382.

Lipke, W., Zwikael, O., \& Henderson, K., Anbari, F. (2009). Prediction of project outcome: The application of statistical methods to earned value management and earned schedule performance indexes. International Journal of Project Management, 27, 400-407.

Moslemi Naeni L., Shadrokh S., \& Salehipour A. (2011). A fuzzy approach for the earned value management. International Journal of Project Management, 29 (6), 764-772.

Moslemi Naeni L., \& Salehipour A. (2011). Evaluating fuzzy earned value indices and estimates by applying alpha cuts. Expert Systems with Applications, 38, 8193-8198.

Noori, S., Bagherpour M., \& Zareei, A. (2008). Applying Fuzzy Control Chart in Earned Value Analysis: A New Application. World Applied Sciences Journal, 3(4), 684-690.

Noori S., Bagherpour, M., \& Zorriasatine, F. (2008). Designing a Control Mechanism for Production Planning Problems By Means of Earned Value Analysis. Journal of Applied Sciences, 8(18), 32213227.

Pajares J., \& López-Paredes A. (2011). An extension of the EVM analysis for project monitoring: The Cost Control Index and the Schedule Control Index. International Journal of Project Management, 29(5), 615-621.

Vandevoorde, S., \& Vanhoucke, M. (2006). A comparison of different project duration forecasting methods using earned value metrics. International Journal of Project Management, 24, 289-302.

Warburton, R. D. H. (2011). A time-dependent earned value model for software projects. International Journal of Project Management. Article in Press. 